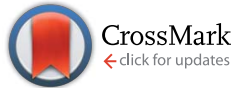

Cite this: RSC Adv., 2017, 7, 4468

Received 25th October 2016

Accepted 3rd January 2017

DOI: $10.1039 / c 6 r a 25806 a$

www.rsc.org/advances

\section{Comparative analysis of stability and biological activities of violacein and starch capped silver nanoparticles $\uparrow$}

\author{
Sania Arif, ${ }^{a}$ Aamina Batool, ${ }^{\text {b }}$ Nauman Khalid, ${ }^{\text {cd }}$ Iftikhar Ahmed $^{\mathrm{e}}$ \\ and Hussnain Ahmed Janjua*a
}

Violacein is a bacterial quorum-sensing chromophore, also referred to as 'purple treasure' for its versatile utility in the pharmaceutical, food, cosmetic and textile industries. Moreover, it provides broad spectrum biological activity that is the subject of expansive scientific research. The major limitation in the drug delivery of violacein is its hydrophobic nature that results in poor bioavailability. Nanoparticles (NPs) coupled with these drugs tend to enhance their delivery, efficacy and safety profiles. In this study, we established that violacein capped silver NPs (vAgNPs) have shown enhanced stability with 3 to 10 times higher therapeutic effect against multidrug resistant bacteria, fungi and algae compared to starch capped silver NPs (cAgNPs). The surface plasmon resonance, size, shape, crystalline nature and capping agent of these NPs were studied with UV-Vis spectroscopy, Scanning Transmission Electron Microscopy, Atomic Force Microscopy, X-ray Diffraction and Fourier Transform Infrared Spectroscopy, respectively. This comparative study examines the efficacy of VAgNPs against CAgNPs and establishes that surface capping of AgNPs with violacein yields conjugative benefits, i.e., strengthening each other's therapeutic effect, increased bioavailability of violacein, higher stability and maneuvering the therapeutic effect of vAgNPs towards Gram positive bacteria.

\section{Introduction}

Violacein, an indole derivative, is synthesized by condensation of two modified tryptophan molecules and composed of oxindole, 2-pyrrolidone and 5-hydroxyindole subunits. ${ }^{1}$ This waterinsoluble violet pigment is soluble in acetone, ethanol, methanol and butanol with a maximum absorption at $585 \mathrm{~nm} .^{2}$ Violacein is also applied in dying synthetic and natural fibers. ${ }^{3}$ It is a photobleaching-resistant chromophore produced as a quorumsensing metabolite by various bacterial strains such as Janthinobacterium lividum, ${ }^{2}$ Chromobacterium violaceum, ${ }^{4}$ and other species. $^{5,6}$ Violacein has shown bactericidal, trypanocidal,

${ }^{a}$ Department of Industrial Biotechnology, Atta-ur-Rahman School of Applied Biosciences, National University of Science and Technology (NUST), Islamabad, Pakistan.E-mail: hussnain.janjua@asab.nust.edu.pk; janjua.hussnain@gmail.com; Tel: +92 323 5680231; +925190856140

${ }^{b}$ School of Chemical and Material Engineering, National University of Science and Technology (NUST), Islamabad, Pakistan

'School of Food and Agricultural Sciences, University of Management and Technology, Lahore 54000, Pakistan

${ }^{d}$ Centre for Chemistry and Biotechnology, School of Life and Environmental Sciences, Deakin University, Waurn Ponds, Victoria, 3216, Australia

${ }^{e}$ Institute of Microbial Culture Collection of Pakistan (IMCCP), National Agricultural Research Centre (NARC), Park Road, Islamabad-45500, Pakistan

$\dagger$ Electronic supplementary information (ESI) available. See DOI: $10.1039 / \mathrm{c} 6 \mathrm{ra} 25806 \mathrm{a}$ mycobactericidal, tumoricidal, antiviral and antioxidant activities. $^{7}$ However, due to its hydrophobic nature, its bioavailability is compromised, which is a main restraint in its drug delivery. ${ }^{8-10}$

Nanocarriers are known to not only enhance the efficacy of drugs but also maneuver its pharmacokinetics. ${ }^{11}$ Although different kinds of nanoparticles (NPs) have been formulated, silver nanoparticles (AgNPs) outclass other NPs in terms of their potential applications ranging from household paint ${ }^{\mathbf{1 2}}$ to artificial prosthetic devices ${ }^{13}$ because of their potent antimicrobial, anticancer and anti-inflammatory properties. ${ }^{\mathbf{1 4 - 1 7}}$ Moreover, their synthesis is eased by using non-toxic and simple reducing agents such as glucose ${ }^{\mathbf{1 8}}$ and these AgNPs are stabilized through surface binding of capping agents, which improves stability, water solubility and also prevent aggregation. ${ }^{19}$ AgNPs have also been capped to deliver therapeutic compounds such as antisense oligonucleotides, ${ }^{20}$ antitumor, ${ }^{21}$ antibiotic drugs ${ }^{22}$ and many more. ${ }^{\mathbf{1 0}}$

Drugs and antibiotics resistance is an increasing threat in the treatment of cancers and pathogenic microbial infections. Due to repeated and abusive use of drugs, the microbes and cancer cells have developed resistance against them and even resistance against AgNPs have been reported. ${ }^{23}$ Therefore, there is a need to find alternative therapies or strengthen the already existing therapy by conjugating one or more drugs with the AgNPs. The surface capping of AgNPs with violacein may have 
conjugative benefits i.e. strengthening each other's therapeutic effects and increasing the bioavailability of violacein. ${ }^{24,25}$

This study aimed to evaluate the violacein capped AgNPs (vAgNPs) as therapeutic agents against starch capped AgNPs (cAgNPs) in terms of antibacterial, antifungal, antialgal and anticancer properties. It was observed that antimicrobial potency of vAgNPs increased from $2 \times$ to $10 \times$. These vAgNPs reduce the required dosage against drug resistant microbes and algae, hence making it possible to eradicate the infections without causing major cytotoxicity. Other than biomedicine, their applications lie in cosmetics and paint industries as sunscreens and antiaging creams due to the absorbance of UV rays, antioxidant and antimicrobial properties of violacein.

\section{Materials and methods}

\section{Identification of violacein producing bacterial strains}

The bacterial strains KH3, KH4 and Isl were isolated from the soil sampled from the Kahuta and Islamabad regions of Pakistan. The rice grains submerged in the moistened soil samples at room temperature, showed purple patches of bacterial growth after 4-5 days. The 16S rRNA gene sequence of the strains was amplified and sequenced using commercial service of Macrogen Inc. Seoul, South Korea (http://www.dna.macrogen.com). The strains were identified based on 16S rRNA gene sequence by comparison with the sequences of type species on EzTaxon-e server (http://eztaxone.ezbiocloud.net) and BLAST (Basic Local Alignment Search Tool) ${ }^{26}$ search on the NCBI (National Center for Biotechnology Information) server. These sequences were submitted to DNA Data Bank of Japan (http://www.ddbj.nig.ac.jp/) and are listed in dendrograms (Fig. 1). Phylogenetic analyses were performed and molecular evolutionary distances were calculated following the Kimura 2-parameter model. The alignment and editing was performed using CLUSTAL X $(1.8 \mathrm{msw})$ and BioEdit. ${ }^{27}$ The phylogenetic trees were constructed using three algorithms: neighbor joining $(\mathrm{NJ}),{ }^{28}$ maximum parsimony $(\mathrm{MP})^{29}$ and maximum likelihood $(\mathrm{ML})^{30}$ using Mega 6 software. ${ }^{31}$ The bootstrap analysis was performed to assess the stability of relationship by performing 1000 re-sampling for the tree topology.

\section{Extraction of violacein pigment}

J. lividum strain Islamabad (Isl) was grown in $100 \mathrm{~mL}$ of Luria Bertani (LB) media at $20^{\circ} \mathrm{C}$ for 5 days and treated for violacein extraction, according to the methods, described previously. ${ }^{32,33}$ Bacterial cells were harvested by centrifugation at $13000 \mathrm{rpm}$ for $10 \mathrm{~min}$. The supernatant was discarded and cell pallet was vortexed in $400 \mu \mathrm{L}$ of $10 \%$ sodium dodecyl sulfate (SDS) for 5 days at room temperature. About $900 \mu \mathrm{L}$ of water-saturated butanol $(1: 2(\mathrm{v} / \mathrm{v}))$ was added, vortexed for $5 \mathrm{~s}$ and centrifuged at $13000 \mathrm{rpm}$ for $5 \mathrm{~min}$. The upper phase (butanol) containing the violacein was collected.

\section{Confirmation and quantification of violacein}

The extracted pigment contained violacein was confirmed through UV-Vis spectroscopy at 300 to $700 \mathrm{~cm}^{-1}$ on UVSpectrophotometer (PG Instruments, Leicestershire, UK). ${ }^{32}$

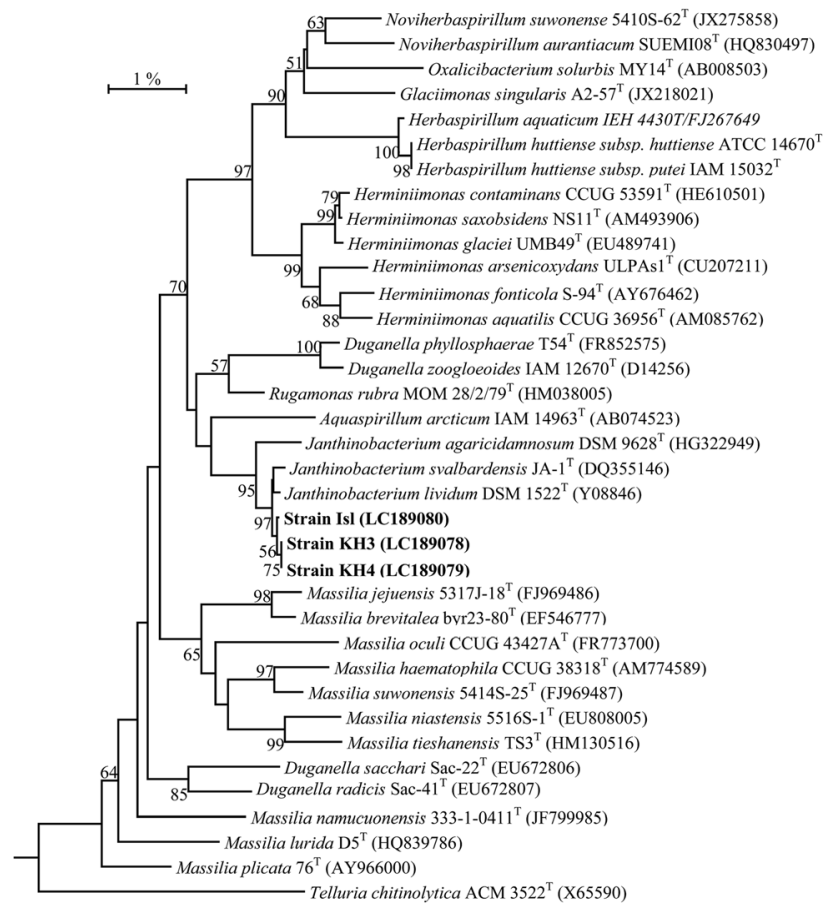

Fig. 1 Neighbor-joining phylogenetic tree constructed based on 16S rRNA gene sequence of isolated strains with the closely related validly published species. The tree was rooted by using Telluria chitinolytica ACM $3522^{\top}$ (X65590) as an out-group. Bootstrap values (only $>60 \%$ are shown) are given at the branching points. Bar indicates $1.0 \%$ sequence divergence.

Butanol solution was taken as reference. The extracted pigment was diluted two times to avoid noise signals. It was further quantified using maximum optical density $\left(\mathrm{OD}_{585}\right)$ and the extinction coefficient of violacein was set at $19.23 \mathrm{~mL} \mu \mathrm{M}^{-1}$ $\mathrm{cm}^{-1}$. The purity of $J$. lividum extract was determined using chloroform and ethanol in $1: 1$ ratio and later, paper chromatography was performed. After half an hour, the paper chromatogram was dried, and analyzed under UV lamp at $254 \mathrm{~nm}$.

\section{Synthesis of violacein capped AgNPs}

AgNPs were reduced through glucose, using method previously explained by Lesli Ortega-Arroyo. ${ }^{18}$ Briefly, $600 \mu \mathrm{L}$ of $1.7 \%(\mathrm{w} / \mathrm{w})$ starch aqueous solution was mixed with $10 \mathrm{~mL}$ of $0.1 \mathrm{M} \mathrm{AgNO}_{3}$. Later $15 \mathrm{~mL}$ aliquot of $0.88 \mathrm{M}$ aqueous solution of D-glucose was added and magnetically stirred for further $3 \mathrm{~h}$. Same protocol was followed for the synthesis of violacein capped AgNPs, except $4 \mathrm{~mL}$ of $\mathrm{J}$. lividium extract solution (violacein concentration: 20 $\mu \mathrm{g} \mathrm{mL}^{-1}$ ) was added in place of starch. In all experiments deionized water was used for preparing solutions.

\section{UV-Vis spectroscopy and purification of AgNPs for confirmatory studies}

The $\mathrm{AgNO}_{3}$ solution presented a pale-yellow color after $1 \mathrm{~min}$, indicating the initial formation of AgNPs. The AgNPs were diluted three times to avoid the noise signals. This was further confirmed by recording UV-visible spectra on UV-Spectrophotometer as 
a function of wavelength from $300-700 \mathrm{~nm}$. $\mathrm{AgNO}_{3}$ solution in deionized water was taken as reference.

After confirmation with UV-Vis spectrophotometry, AgNPs were centrifuged at $15000 \mathrm{rpm}$ for $15 \mathrm{~min}$. Supernatant was discarded and pellet was suspended in deionized water. Steps of centrifugation and suspension were repeated three times to remove impurities. In the end, purified colloidal solution of AgNPs was obtained which was characterized through FTIR, AFM and SEM to confirm the stability of synthesized AgNPs in deionized water.

\section{Atomic force microscopy (AFM) and scanning transmission electron microscopy (STEM)}

$50 \mu \mathrm{L}$ of colloidal NPs solution was diluted in almost $5 \mathrm{~mL}$ of deionized water and sonication was performed for $1 \mathrm{~h}$. For AFM, the AgNPs colloidal suspension was dried on silicon wafer in a desiccator and dried overnight. The surface properties and size of biosynthesized NPs were visualized by Scanning Probe Microscopy JSPM-5200 (JOEL, Japan). The scanning was performed in tapping mode. 3D topographical images were obtained. The height, size and particle size measurements of the AgNPs were made using SPIP 6.2.8 software.

The violacein and starch capped silver nanoparticles were deposited onto a copper grid via drop casting method and were then analyzed using scanning electron microscope (Nova NanoSEM 450) operating at $10 \mathrm{kV}$ and working distance of $5 \mathrm{~mm}$ using STEM detector. The obtained STEM images of AgNPs were then processed using Image-J software for their histogram analysis.

\section{Fourier transform infrared spectroscopy (FTIR)}

Pellet of $\mathrm{KBr}$ was prepared using hydraulic press and 2-3 drops of violacein and AgNPs were added separately and measurements were carried out using Perkin-Elmer Spectrum-100 FTIR using scanning wavelength of $450-4000 \mathrm{~cm}^{-1}$ with a resolution difference of $1 \mathrm{~cm}^{-1}$. Manual peak picking method was used for the analysis of results and the peaks obtained were compared with standard functional group charts.

\section{X-ray diffraction (XRD) studies}

The samples were air dried, powdered and used for XRD analysis. $\mathrm{X}$-ray diffraction patterns were recorded in the scanning mode on WinX'POW, X-ray Diffractometer System (STOE: theta/theta, Germany) operated at $40 \mathrm{kV}$ and a current of $30 \mathrm{~mA}$ with $\mathrm{Cu}$ $\mathrm{K} \alpha$ radiation $(\lambda=1.54064 \AA)$. The diffraction intensities were recorded from $30^{\circ}$ to $80^{\circ}$, in $2 \theta$ angles. The diffraction intensities were compared with the standard JCPDS files. The average size of the NPs can be estimated using the Debye-Scherrer equation:

$$
D=k \lambda / \beta \cos \theta
$$

where $D$ is the thickness of the nanocrystal, $k$ is the constant, $\lambda$ corresponds to wavelength of X-rays, $\beta$ shows width at half maxima of (111) reflection at Bragg's angle $2 \theta$ and $\theta$ represent Bragg angle. Moreover, the size of the AgNPs was made from the line broadening of the (111), (200), and (220) reflection using the Debye-Scherrer formula through X'Pert High Score Plus software.

\section{Stability profile of AgNPs}

The effect of pH, salt, heat and time on AgNPs was assessed according to the following protocols modified from Naz, et al. ${ }^{34}$

pH effect. To study the $\mathrm{pH}$ effect, $2 \mathrm{~mL}$ of freshly prepared AgNPs was taken and $\mathrm{pH}$ was recorded as 7 . The $\mathrm{pH}$ ranging from 10-13 was adjusted with $1 \mathrm{M} \mathrm{NaOH}$ solution while $\mathrm{pH}$ 2-7 was maintained with $1 \mathrm{~N} \mathrm{HCl}$. The UV-Vis spectra of resulting solutions were recorded after $24 \mathrm{~h}$.

Salt effect. Effect of high concentration of NaCl (2-4 M) on synthesized AgNPs was studied. For this purpose, $2 \mathrm{~mL}$ of 2,3 and $4 \mathrm{M} \mathrm{NaCl}$ solutions were added to $2 \mathrm{~mL}$ of freshly prepared AgNPs. The resulting solution was kept at room temperature for $24 \mathrm{~h}$ and its UV-Vis spectrum was recorded.

Heat effect. The effect of heat on synthesized AgNPs was studied by heating $10 \mathrm{~mL}$ of freshly prepared solution up to $100{ }^{\circ} \mathrm{C}$ for $30 \mathrm{~min}$. The NPs were analyzed for UV-Vis spectrophotometry.

Age effect. The aging effect of AgNPs was studied after 4 months of synthesis and compared to the previously synthesized AgNPs through UV-Vis spectrum.

\section{Biological activities of synthesized AgNPs}

The solution of AgNPs was centrifuged at $15000 \mathrm{rpm}$ for 15 min, clear supernatant was discarded and dry weight was calculated. Serial dilutions of AgNPs from the stock solution were prepared in deionized water and concentrations were calculated. The concentrations for bioassays prepared were $10000,1000,750,500,250,100,75,50, \mu \mathrm{g} \mathrm{mL}{ }^{-1}$.

Antibacterial activity against $\mathbf{E}$. coli, $\mathbf{P}$. aeruginosa and $\mathbf{S}$. aureus. Multidrug resistant clinical strains of E. coli, S. aureus and $P$. aeruginosa were obtained from Phage Lab at Atta-urRahman School of Applied Biosciences NUST, Pakistan. LB medium was used for the growth of bacteria's. ${ }^{35}$ Antibacterial activity of cAgNPs and vAgNPs was determined with disc diffusion method. To avoid false results, Mc Farland Standard of 0.5 turbidity was prepared for adjusting cell density of bacterial cultures to $1 \times 10^{8} \mathrm{CFU} \mathrm{mL}{ }^{-1} \cdot{ }^{36}$ Discs of approximately $6 \mathrm{~mm}$ in size were prepared from Whattman filter paper grade 4 , and were autoclaved. A single disc was placed on the agar inoculated with the bacterium by using a sterile syringe (BD $5 \mathrm{~mL}$ syringe, REF-305719, Becton \& Dickinson, Pakistan), $20 \mu \mathrm{L}$ of each dilution of AgNPs and violacein was dispensed and dried onto the swabbed plates. Plates were incubated overnight at $37{ }^{\circ} \mathrm{C}$ and diameters of zone of inhibition at different concentrations were recorded. Each experiment was performed in duplicates.

Negative control of deionized water was used in antibacterial assay of AgNPs. Butanol, AgNPs and deionized water were also used as controls. Statistical analysis was carried out for the estimation of zone of inhibition for duplicate experiment; average \pm standard deviation was calculated by using Graphpad Prism 6.0. ${ }^{37}$ Statistical testing such as paired $T$ test (One Tailed) was performed to get the $p$ values.

Antifungal activity of AgNPs. Sabouraud dextrose agar (Oxoid, UK) was used for growth of fungus. $20 \mathrm{~L}$ of different dilutions of AgNPs and violacein were poured onto discs. Plates were incubated at $30{ }^{\circ} \mathrm{C}$ for 3 days. Each experiment was carried 
out in duplicates and zones of inhibition were recorded. ${ }^{38}$ Statistical analysis was carried out for estimation of zone of inhibition for duplicate experiment; average \pm standard deviation was calculated by using Graphpad Prism 6.0. ${ }^{37}$

Anti-algal activity. Basal Bold Media (BBM, Phyto Technology Laboratories, Australia) was prepared with 1\% agarose for growth of algae. Anti-algal activity was assessed through disc diffusion assay, where $200 \mu \mathrm{L}$ of BBM, previously incubated with algae at room temperature and was spread on plates and paper discs. $20 \mu \mathrm{L}$ of different dilutions were poured onto discs. Latter plates were incubated at $25{ }^{\circ} \mathrm{C}$ for 5 days. ${ }^{39}$ Each experiment was carried out in duplicates and minimal inhibitory concentration was analyzed. Statistical analysis was carried out for the estimation of zone of inhibition for duplicate experiment; average \pm standard deviation and paired $T$ test (One Tailed) was calculated using Graphpad Prism 6.0. ${ }^{37}$

\section{Results and discussion}

\section{Identification of isolated strains by $16 S$ rRNA sequencing}

Based on 16S rRNA gene sequence analysis, strains KH3, KH4 and Isl were closely related to the cluster of type species: Janthinobacterium lividum (Y08846), J. svalbardensis (DQ355146) and J. agaricidamnosum (HG322949) and the sequence similarity for these strains with J. lividum DSM $1522^{\mathrm{T}}$ (Y08846) was found to be $99.5 \%, 99.6 \%$ and $99.7 \%$ respectively, claiming their species status as J. lividum. A NJ phylogenetic tree showed that isolated strains clustered coherently with the clade comprising of strains of the genus Janthino bacterium at high bootstrap value of $95 \%(0.1)$. A similar tree topology of these strains was also observed with the same species when the phylogenetic analyses were performed using other algorithms: MP and ML (Fig. S1 and S2†).

\section{UV-Vis spectroscopy and paper chromatography of crude extract}

Absorption spectrum of crude extract extracted from J. lividium (Isl) shows maximum absorption at $585 \mathrm{~nm}$ (Fig. 2) and the peak features are similar with that of violacein extracted from Chromobacterium violaceum (Fig. 2), ${ }^{32}$ which depicts that violet pigmentation of $J$. lividium's extract is due to violacein. Furthermore, the purity was assessed on paper chromatogram under UV lamp at $254 \mathrm{~nm}$, which indicated multiple spots and suggests the presence of other metabolites in addition to violacein such as deoxyviolacein, ${ }^{40}$ FK228 (ref. 41) and others.

\section{Synthesis of violacein capped AgNPs}

Starch and violacein were used to cap the glucose reduced AgNPs. Preliminary confirmation of AgNPs synthesis, was carried out by observing color change in the reaction mixture from colorless to light brown and finally to yellowish-brown after $3 \mathrm{~h}$ of stirring. The confirmation in color change and synthesis of AgNPs was assessed through UV-Vis spectroscopy (Fig. 3). The position of absorbance peak was in the range of $400 \mathrm{~nm}$ to $500 \mathrm{~nm}$ indicates the synthesis of AgNPs. ${ }^{42}$ If absorption peak with wavelength of AgNPs shifts from $\sim 400$ to

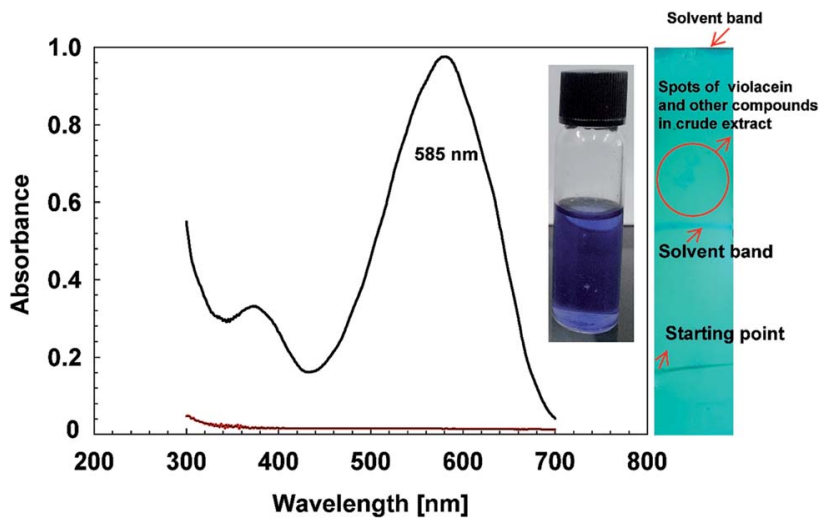

Fig. 2 UV-Vis spectrum and chromatogram of crude extract of $\mathrm{J}$. lividium strain Isl. (-) Represents the crude extract containing violacein extracted from J. lividium strain Isl, while (-) shows the absorption spectrum of butanol. The maximum absorbance at $585 \mathrm{~nm}$, was a characteristic feature of violacein pigment. The inserted image crude extract having violet pigment due to violacein. The paper chromatogram shows multiple spots which indicates the presence of other components along with violacein.

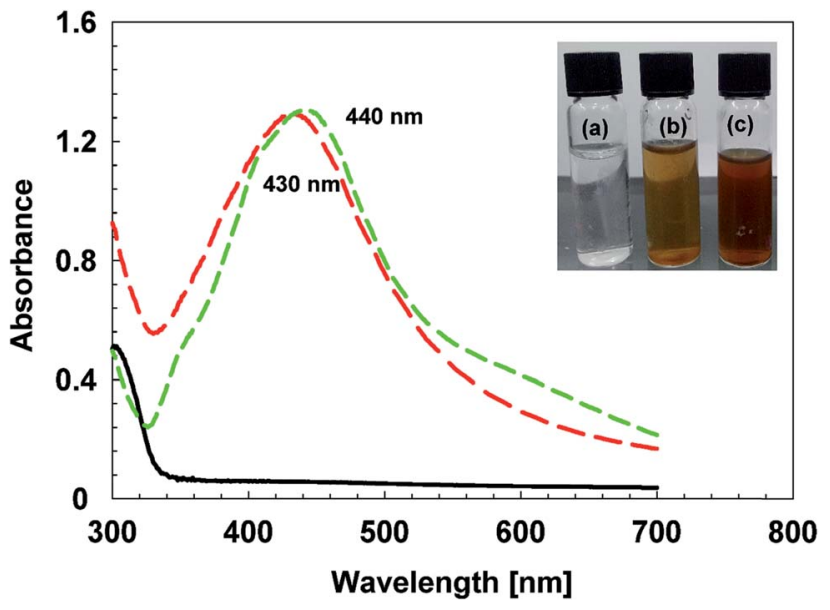

Fig. 3 UV-Vis spectra of AgNPs. The spectrum line marked with $(---)$ and $(----)$ corresponds to the UV-Vis spectra of VAgNPs and cAgNPs respectively. The baseline (-) shows absorption spectrum of $\mathrm{AgNO}_{3}$. The inserted image shows (a) $\mathrm{AgNO}_{3}$ observes no color change while (b) light brown color signifies the synthesis of cAgNPs and (c) dark brown color indicates the synthesis of vAgNPs.

$\sim 500 \mathrm{~nm}$ it indicates the particle size increases from $\sim 2$ to $\sim 70 \mathrm{~nm} .{ }^{43}$ Larger sized NPs were formed if the peak wavelength lies towards red wavelength. In case of vAgNPs the maximum absorption peak was at $430 \mathrm{~nm}$, compared to that of cAgNPs (used as control AgNPs in further experiments), the peak lies at $440 \mathrm{~nm}$, showing vAgNPs are relatively smaller sized NPs than cAgNPs.

\section{Atomic force microscopy}

Three-dimensional topographical images captured by AFM verify the assumptions made on the results of UV spectrum that vAgNPs have smaller diameter than cAgNPs (Fig. 4). Both types 

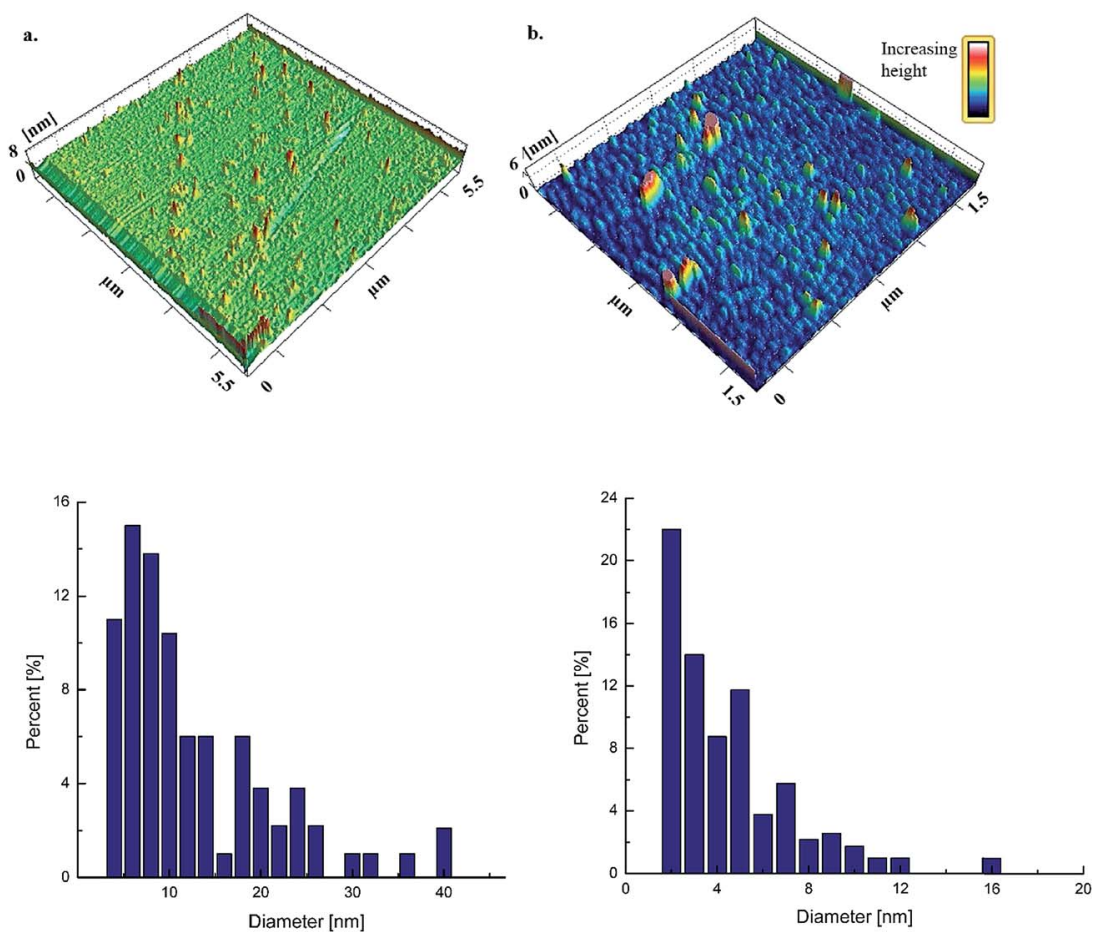

Fig. 4 Three dimensional topographical images and histograms of AgNPs. (a) cAgNPs and (b) vAgNPs. The scan size and height was $5.5 \mu \mathrm{m} / 8 \mathrm{~nm}$ and $3.5 \mu \mathrm{m} / 6 \mathrm{~nm}$ for cAgNPs and vAgNPs respectively. The bar at upper right corner represents color change in the scans with the increasing height. The bar charts represent the histograms of AgNPs where diameter is plotted against percentage abundance.

of AgNPs are smooth surfaced, spherical shaped, without any defects (pinholes or cracks). The topographical images also agreed that particles are not forming agglomerates, and AgNPs formed smooth film on the glass surface. Particle size analysis of each AgNPs showed that cAgNPs are of $1-40 \mathrm{~nm}$ diameter and vAgNPs are of $1-15 \mathrm{~nm}$ diameter (Fig. 4) with mean values $19 \pm$ 9 and $8 \pm 4 \mathrm{~nm}$ respectively.
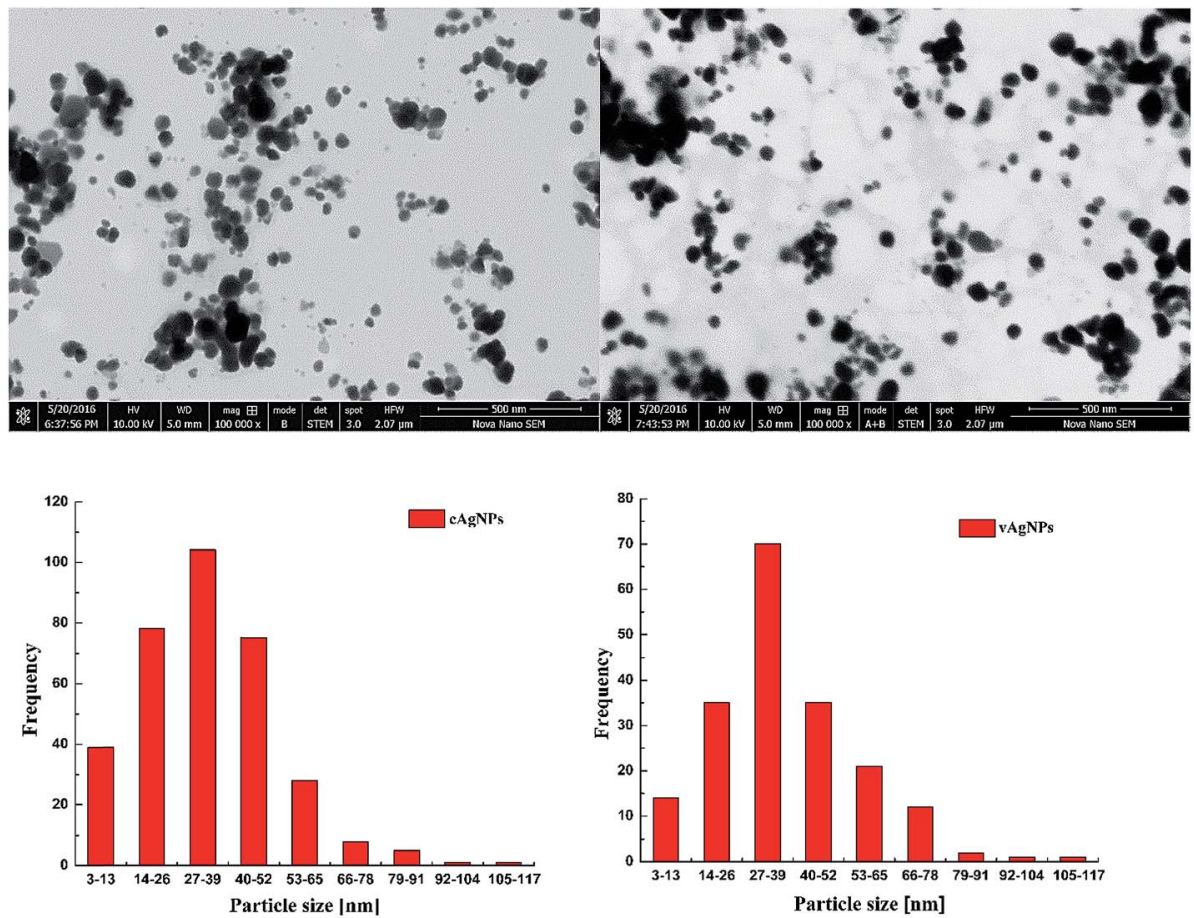

Fig. 5 STEM images of AgNPs, these images were captured at high resolution of $500 \mathrm{~nm}$. The sizes of NPs were presented on the micrographs of cAgNPs and vAgNPs calculated with reference to $500 \mathrm{~nm}$ scale. 


\section{Scanning transmission electron microscopy}

STEM images indicate uniform spherical shaped synthesized AgNPs in colloidal aqueous solution as observed in Fig. 5. The histograms are coherent with the UV-Vis spectrums, the polydispersed NPs are formed in the range of 3-117 as depicted by the broad peaks at 430 and $440 \mathrm{~nm}$ in the UV-Vis spectrums. The average size of cAgNps and vAgNPs was calculated to be
$37 \mathrm{~nm}$ greater than $34 \mathrm{~nm}$ as predicted in AFM and UV-Vis spectroscopy.

\section{Fourier transform infrared spectroscopy}

FTIR measurements were performed to acquire information about the stabilizing chemical groups present at the surface of AgNPs. ${ }^{44}$ In FTIR spectrum of $J$. lividium extract (Fig. 6a), the IR

(a)

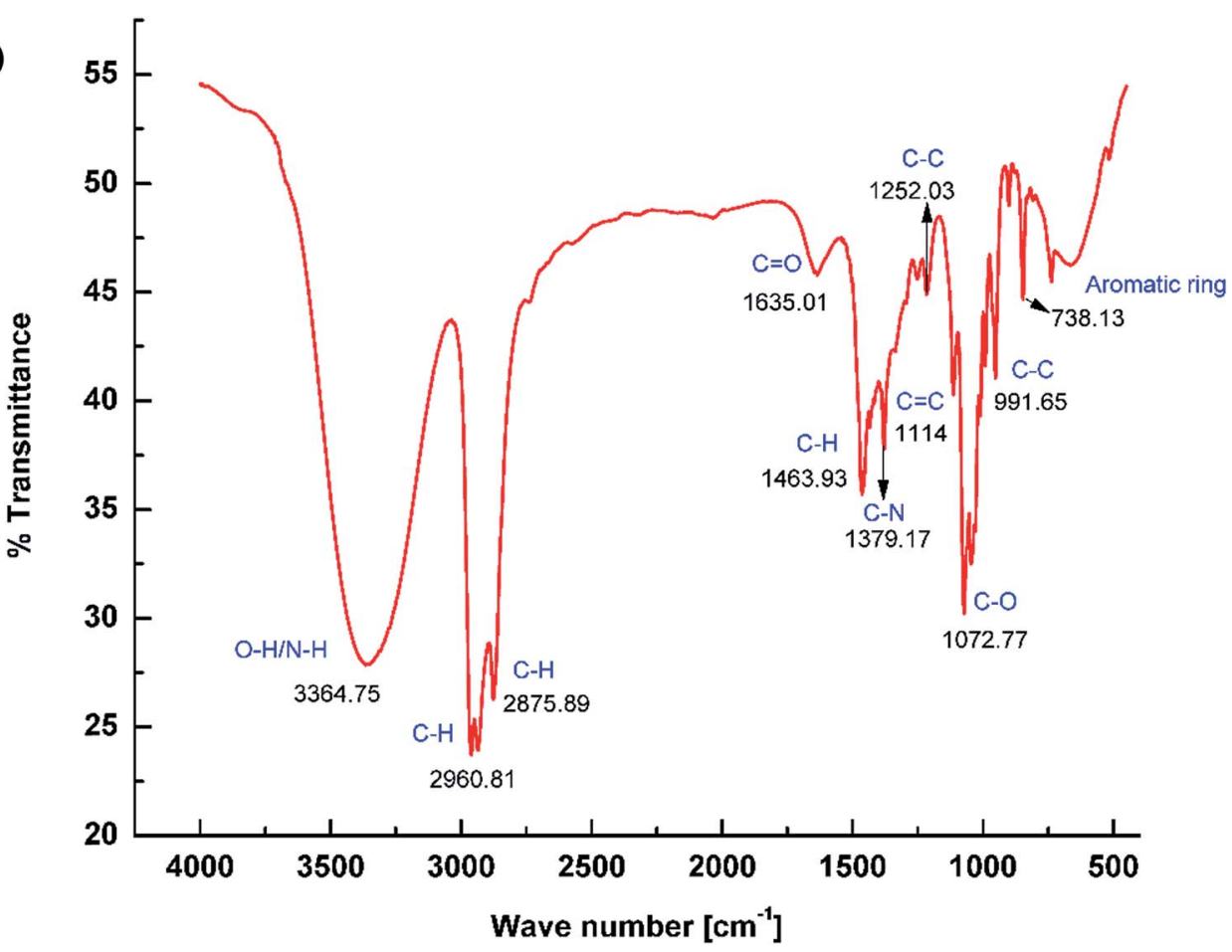

(b)

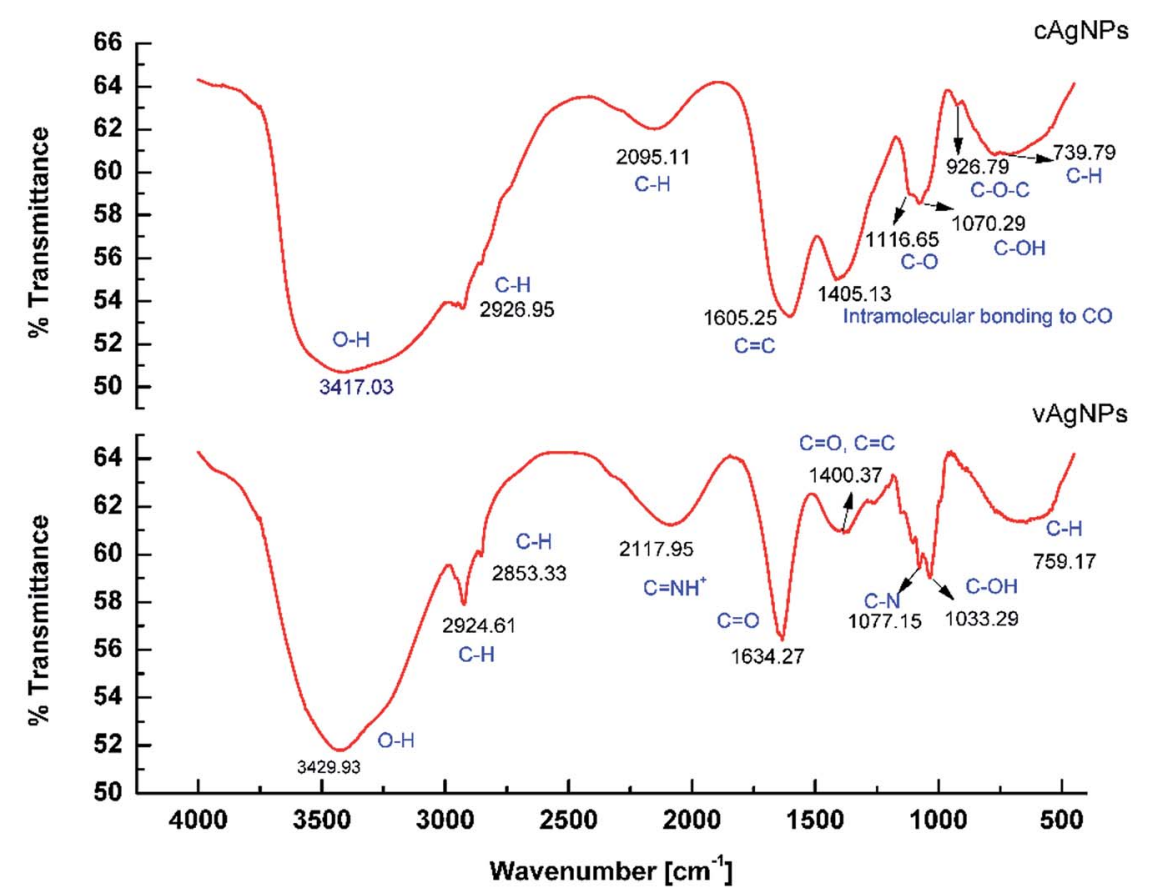

Fig. 6 FTIR studies with AgNPs. (a) FTIR spectra of J. lividium extract. (b) FTIR spectrum of cAgNPs and vAgNPs. The peaks correspond to the variable functional groups of starch and violacein. 
bands at $3364.75 \mathrm{~cm}^{-1}, 2924 \mathrm{~cm}^{-1}, 1635 \mathrm{~cm}^{-1}, 1379.17 \mathrm{~cm}^{-1}$ and $711 \mathrm{~cm}^{-1}$ correspond to the vibrations of functional groups, $\mathrm{N}-\mathrm{H}$ overlapping with $\mathrm{O}-\mathrm{H}$ stretching, $\mathrm{C}-\mathrm{H}, \mathrm{C}=\mathrm{O}$ of carbonyl group. The $\mathrm{C}-\mathrm{N}$ of indole ring and $\mathrm{C}-\mathrm{C}$ of aromatic ring was related to violacein. ${ }^{45,46}$ This indicates that violacein is present in J. lividium extract, while presence of other peaks also suggests that other organic components in extract are a part of it. ${ }^{46}$

Analysis of cAgNPs indicated capping of starch as the vibration modes such as skeletal mode vibrations of $\alpha-1,4$ glycosidic linkage, (C-O-C) $926 \mathrm{~cm}^{-1}$, intermolecular bonding of CO $1405 \mathrm{~cm}^{-1}$ and C-C of ring structure 739 etc., refer to starch. ${ }^{18}$ In case of FTIR spectra of VAgNPs, violacein was capped on the surface of AgNPs, as IR bands at $2117.95 \mathrm{~cm}^{-1}, 1634$ $\mathrm{cm}^{-1}, 1077.15 \mathrm{~cm}^{-1}$ and $759 \mathrm{~cm}^{-1}$ correspond to the vibrations of functional groups $\mathrm{C}=\mathrm{NH}^{+}, \mathrm{C}=\mathrm{O}$ of carbonyl group, $\mathrm{C}-\mathrm{N}$ of indol ring and $\mathrm{C}-\mathrm{C}$ skeleton vibration of aromatic ring (Fig. 6b) related to violacein. ${ }^{45,46}$

\section{X-ray diffraction}

XRD patterns of AgNPs were presented in Fig. 7. Three to four diffraction peaks appear (at $2 \theta$ ) $38^{\circ}, 44^{\circ}, 64^{\circ}$ and $77^{\circ}$, which correspond, respectively, to the planes (111), (200), (220), (311), and (222) of face-centered cubic (fcc); the typical crystalline
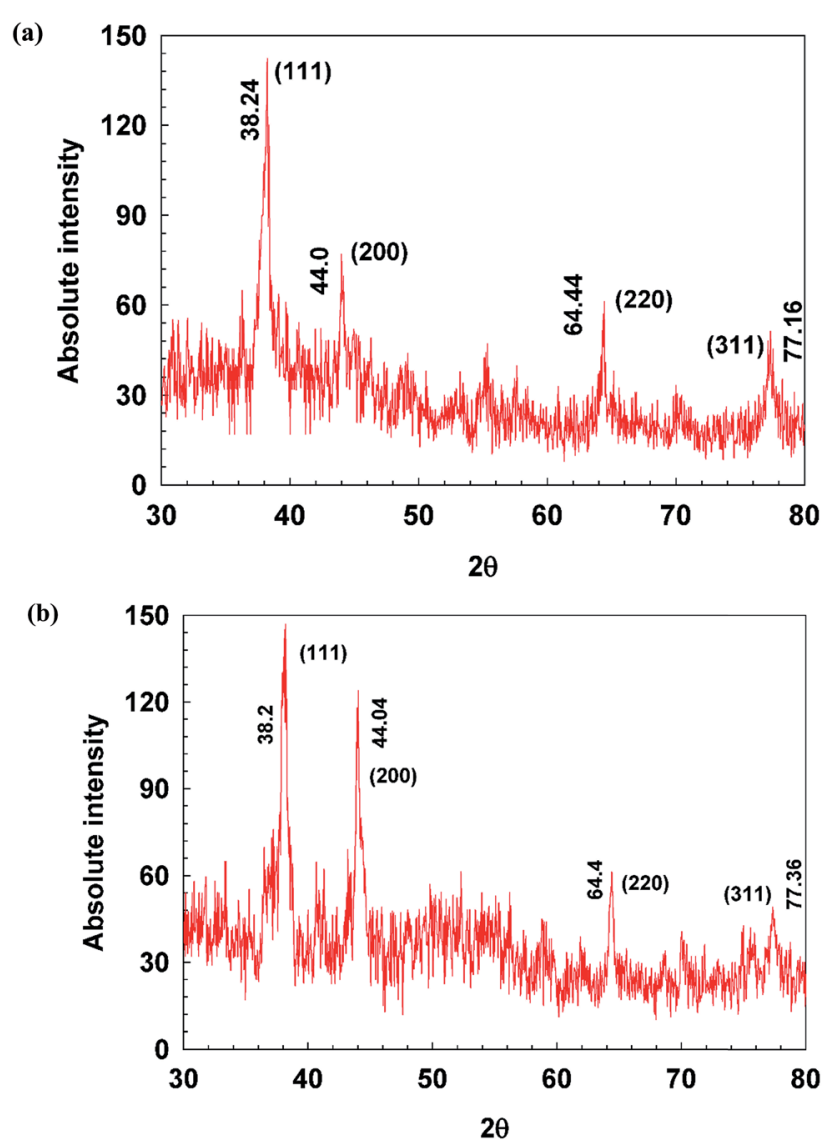

Fig. 7 XRD patterns of AgNPs. (a) cAgNPs and (b) vAgNPs. The sample was scanned from 0 to 80 degree at angle 2 theta. The labeled peaks refer to the phases matched with that of typical crystalline phases of AgNPs. structure of Ag. ${ }^{18}$ There were greater number of peaks in vAgNPs which may due to the capping of violacein and other components present in J. lividium extract. The average crystalline size of cAgNPs and vAgNPs derived from the Debye-Scherrer equation were $44 \mathrm{~nm}$ and $30 \mathrm{~nm}$, which are consistent with the AFM and STEM results that cAgNPs are larger in size (Table S1 $\dagger$ ).

\section{Aging and stability profile of AgNPs}

The aging and stability profile of AgNPs was assessed under the influence of temperature, salt and $\mathrm{pH}$.

Age effect. Aging of AgNPs was observed after the period of 4 months, cAgNPs began to show the signs of agglomerations as the peaks were shifted from $440 \mathrm{~nm}$ to $480 \mathrm{~nm}$ (Fig. S3a $\dagger$ ). Additionally, the peak broadening of old cAgNPs showed that aging also disrupts the monodispersity, i.e. NPs of broad size range are formed with the passage of time. ${ }^{47}$ In case of vAgNPs, the NPs were quite resistant to aging (Fig. S3b广) and as there was no significant difference in peak width and position, this indicates that violacein capped AgNPs were more stable over a period and prevent aggregation of AgNPs.

The color change also confirms these findings, (Fig. S3†), as in cAgNPs, the color becomes turbid brownish-grey, as maximum absorbance has shifted towards $500 \mathrm{~nm}$ and rest of transmitted wavelengths are perceived as turbid brownish grey color. ${ }^{47}$ Similarly, the peak was shifted towards red wavelength and dark brown color appears.

Heat effect. The AgNPs were heated at $60^{\circ} \mathrm{C}$ for half an $\mathrm{h}, \mathrm{UV}$ Vis spectra showed that cAgNPs were more resistant to heat (Fig. S4a †). In contrast, the vAgNPs (Fig. S4b†) showed not only peak shift from $430 \mathrm{~nm}$ to $440 \mathrm{~nm}$ but also broadening of peak was observed. This can be due to the susceptibility of metabolites present in J. lividium to the heat.

Salt effect. The agglomerates of AgNPs are formed when their colloidal solutions were treated with 2,3 and $4 \mathrm{M}$ of $\mathrm{NaCl}$ (Fig. 8). The peaks were clearly dissolved which signifies that NPs have escaped the nanoscale. Peak shifting from $400 \mathrm{~nm}$ to $600 \mathrm{~nm}$ was clear sign of agglomeration. This can be observed in case of cAgNP, when treated with $2 \mathrm{M} \mathrm{NaCl}$, peak at $440 \mathrm{~nm}$ shifted to $580 \mathrm{~nm}$, illustrated the agglomeration of AgNPs occurs. ${ }^{48}$ Similar, results were observed with vAgNPs too, the peak at $430 \mathrm{~nm}$ (Fig. 8b) was diminished completely.

pH effect. cAgNPs (Fig. 9a) are more tolerant to $\mathrm{pH}$ change, and survive in $\mathrm{pH}$ range $2-10$ while vAgNPs are tend to make agglomerates and exist in short range of $\mathrm{pH}, 4-10$, as violacein is itself tolerant to short range of $\mathrm{pH} 5-9 .^{7}$ Increasing $\mathrm{pH}$ also shift peaks towards $600 \mathrm{~nm}$ which was a sign of agglomeration and peak broadening indicates the increase in the size range of AgNPs (Fig. 9b). Both AgNPs were most stable at neutral pH 7. After studying stability of vAgNPs and cAgNPs, both AgNPs were maintained at room temperature, $\mathrm{pH} 7$, diluted with deionized water and used within a month of their synthesis to assess their biomedical applications.

\section{Applications of violacein capped AgNPs}

Starch itself is non-toxic, biocompatible, and doesn't possess any antibiological activities, ${ }^{\mathbf{4 9}}$ therefore cAgNPs were ideal 

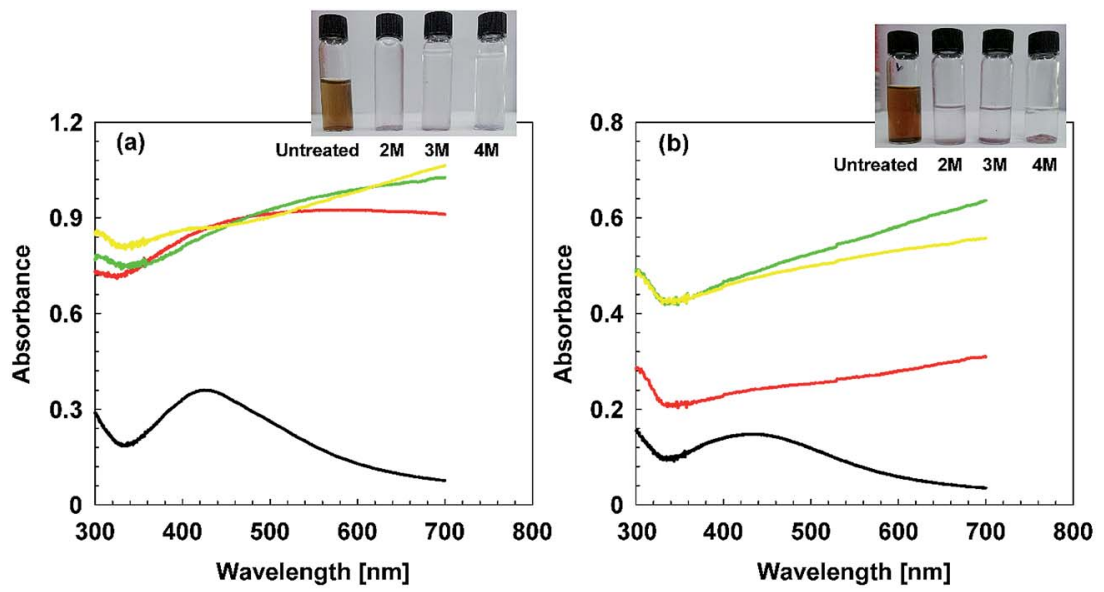

Fig. 8 UV-Vis spectra indicating effect of high concentration of $\mathrm{NaCl}$ on AgNPs. (a) cAgNPs and (b) vAgNPs. (一) Denote absorbance for untreated samples, $(-2 \mathrm{M},(-) 3 \mathrm{M}$ and $(-)$ denote absorbance for $4 \mathrm{M}$.

candidate to be compared with violacein capped AgNPs (vAgNPs) to assess their antibacterial, antifungal, antialgal and anticancer activities.

(a)

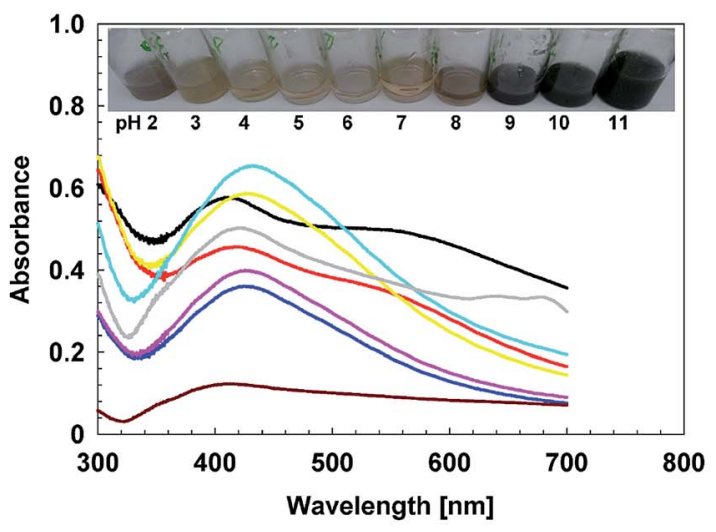

(b)

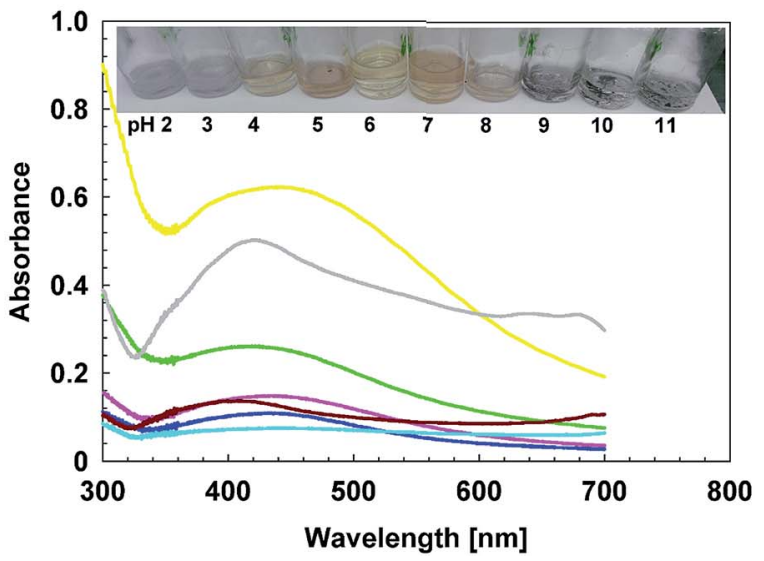

Fig. 9 UV-Vis spectra indicating effect of increasing $\mathrm{pH}$ on AgNPs. The inserted images show color change in AgNPs at $\mathrm{pH} 2-11$. cAgNPs were more tolerant to $\mathrm{pH}$ change, and survive in $\mathrm{pH}$ range $2-10$ while vAgNPs exist in short range of $\mathrm{pH}, 4-10$. (a) cAgNPs and (b) vAgNPs.

$(\longrightarrow)$ Show absorbance at $\mathrm{pH} 2,(\longrightarrow) \mathrm{pH} 3,(-) \mathrm{pH} 4,(-) \mathrm{pH}$,

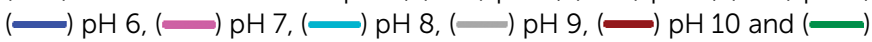
denote absorbance at $\mathrm{pH} 11$.
Antibacterial activity. vAgNPs showed significant antibacterial properties, compared to the cAgNPs against all three strains of E. coli, P. aeruginosa and $S$. aureus as the $p$ values were $<0.05$ (Fig. 10a-c). Dose dependent increase in zone of clearance was observed which indicates that there was directly proportion relationship between the concentrations of AgNPs, which was irrespective of the capping components. However, in case of vAgNPs antibacterial zones were not only bigger but MICs were also comparatively very low up to $25 \mu \mathrm{g} \mathrm{mL}^{-1}$, indicating conjugating action between AgNPs and violacein. For all the three strains of $E$. coli, MRSA and P. aeruginosa, the MICs for vAgNPs were 2 to 10 times, 7.5 to 10 times and 4 to 1.3 times less than cAgNPs respectively. This corresponds to the susceptibility pattern, $S$. aureus $>P$. aeruginosa $>E$. coli, which indicates that the capped violacein directs the therapeutic effect of AgNPs towards Gram positive bacteria, since violacein is more effective for Gram positive than Gram negative strains. ${ }^{50}$ MICs of AgNPs was found to be variable for the different strains of each species, this can be due to the differences in pan genomes such as silver resistive genes, which are acquired through horizontal gene transfer. ${ }^{51}$

The MICs for crude violacein has been found to be lower up to $500 \mathrm{ng} \mathrm{mL}^{-1}$ than that of purified violacein, $15 \mu \mathrm{g} \mathrm{mL}{ }^{-1}(S$. aureus), $15 \mu \mathrm{g} \mathrm{mL}{ }^{-1}$ (P. aeruginosa) and $>50 \mu \mathrm{g} \mathrm{mL}^{-1}$ (E. coli) $)^{52}$ it might be due to the presence of other components such as deoxyviolacein, oxyviolacein, FK228, etc..$^{53}$ having antibiological properties as well.

Antifungal activity. In comparison to antibacterial activity, there was antifungal activity at high doses of $10 \mathrm{mg}$ and $1 \mathrm{mg}$ of vAgNPs. cAgNPs didn't show any antifungal activity against three different species even at high concentrations of 10000 and $1000 \mu \mathrm{g} \mathrm{mL} \mathrm{mL}^{-1}$ (Fig. S5†). Susceptibility for AgNPs, was found to be variable for the different fungal strains, this can be due to the difference in cell walls and genomic structure. ${ }^{54,55}$ In all strains, vAgNPs found to be effective than cAgNPs. The overall susceptibility pattern of fungal species against AgNPs was Aspergillus tamari $>$ Aspergillus tubingensis $>$ Fusarium proliferatum. Remarkable antifungal activity of crude violacein against all three-fungal species at $5 \mu \mathrm{g} \mathrm{mL} \mathrm{m}^{-1}$ MIC, also justify 

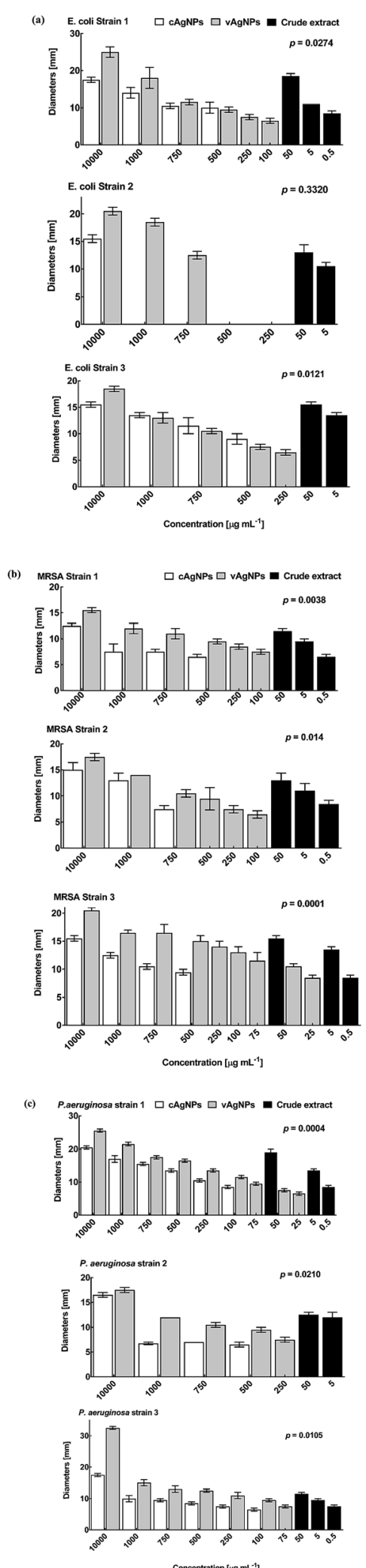

Fig. 10 Antibacterial activities against three strains of (a) E. coli (b) MRSA and (c) P. aeruginosa. The error bars show the standard error of mean.

\section{Dictyosphaerium 6-8 $\square$ cAgNPs $\square$ vAgNPs $\square$ Crude extract}
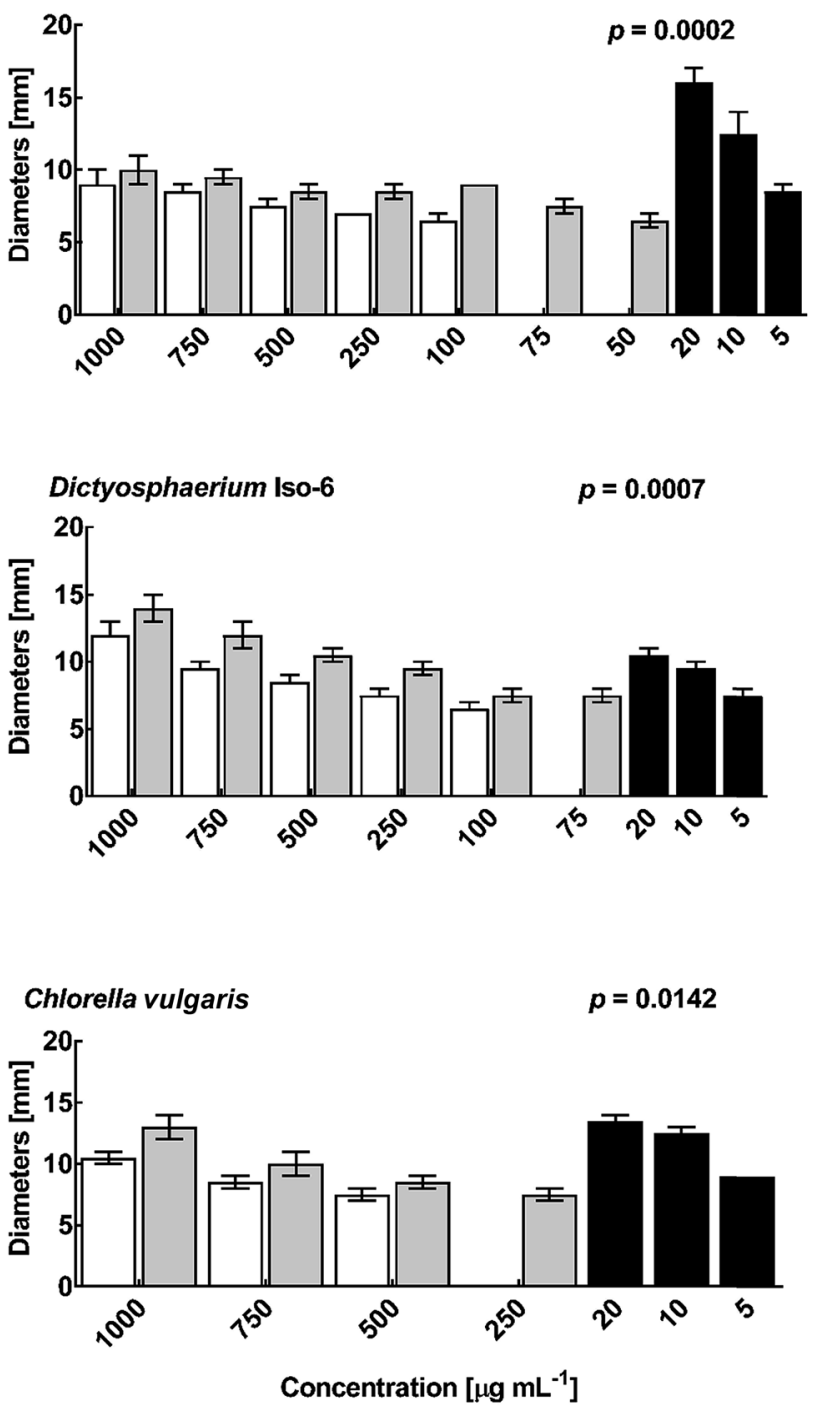

Fig. 11 Antialgal activity of AgNPs and crude violacein. The antialgal activities were confirmed against two other strains Dictyosphaerium sp. strain DHM 2 (LC159306) and Dictyosphaerium sp. strain DHM 1 (LC159305).

that due to broad spectrum of extracts of the J. lividium strains these are effective cutaneous antifungal therapy for amphibians. Since violacein averts mortality and morbidity caused by $B$. dendrobatidis on salamander's skin at about $18 \mu \mathrm{M}$ concentration. ${ }^{56}$ In human pathogens, Trichophyton rubrum, a dermatophytic fungi, causes superficial mycoses in skin, nails and hairs, etc., the MIC of violacein is reported as $32 \mu \mathrm{g} \mathrm{mL} \mathrm{m}^{-1}$. $^{57}$

Antialgal activity. vAgNPs showed significant antibacterial properties, compared to the cAgNPs against all three species of algae (Fig. 11). The $T$-test verified that vAgNPs were more effective than cAgNPs $(p<0.05)$. A dose dependent increase in zone of clearance was observed which indicates that there was direct proportional relationship between concentrations of AgNPs and MICs. The MICs of vAgNPs for Dictyosphaerium sp. strain DHM 1, Dictyosphaerium sp. strain DHM 2 and Pectinodesmus sp. strain PHM 3 were $4,1.3$ and 2 times less than cAgNPs respectively, 
which indicates that there was strengthening effect at the action of AgNPs when coupled with crude violacein. Furthermore, the crude extract also showed significant antialgal property with 20 , 10 and $5 \mu \mathrm{g} \mathrm{mL}{ }^{-1}$ concentration of violacein. The overall susceptibility pattern of algal species against AgNPs was Dictyosphaerium sp. strain DHM1 > Dictyosphaerium sp. strain DHM2 $>$ Pectinodesmus sp. strain PHM 3.

\section{Conclusion}

Numerous studies have been done on green synthesis of AgNPs, but very few studies give insights to the properties imparted to the AgNPs by the capping agents. In the present study, comparative analysis of starch and violacein as capping agents of AgNPs, in terms of their stability and antibiological properties was done, to find out how capping effects the therapeutic mechanism of AgNPs. The results showed that capping of AgNPs with violacein, not only enhanced the stability and antimicrobiological properties of AgNPs. MICs of violacein capped AgNPs are far lower than starch capped AgNPs, which indicates the enhanced activity between violacein and AgNPs against bacteria, fungus, and algae. Moreover, violacein capping also engineers the therapeutic mechanism of AgNPs, making them more selective towards Gram positive bacteria. Broad range of activities against Gram positive and negative bacteria, antifungal, and antialgal activities were well observed and approved violacein as an impending candidate for biomedicine, drug delivery and therapeutic mediator.

\section{References}

1 H. Wang, P. Jiang, Y. Lu, Z. Ruan, R. Jiang, X.-H. Xing, K. Lou and D. Wei, Biochem. Eng. J., 2009, 44, 119-124.

2 F. Pantanella, F. Berlutti, C. Passariello, S. Sarli, C. Morea and S. Schippa, J. Appl. Microbiol., 2007, 102, 992-999.

3 A. Shirata, T. Tsukamoto, H. Yasui, T. Hata, S. Hayasaka, A. Kojima and H. Kato, Jpn. Agric. Res. Q., 2000, 34, 131-140. 4 T. Hoshino, Appl. Microbiol. Biotechnol., 2011, 91, 1463-1475. 5 M. Durán, A. N. Ponezi, A. Faljoni-Alario, M. F. S. Teixeira, G. Z. Justo and N. Durán, Med. Chem. Res., 2012, 21, 15241532.

6 Y. Jiang, F. Sigmund, J. Reber, X. L. Deán-Ben, S. Glasl, M. Kneipp, H. Estrada, D. Razansky, V. Ntziachristos and G. G. Westmeyer, Sci. Rep., 2015, 5, 11048.

7 W. A. Ahmad, N. Z. Yusof, N. Nordin, Z. A. Zakaria and M. F. Rezali, Appl. Biochem. Biotechnol., 2012, 167, 12201234.

8 R. Suryawanshi, C. Patil, H. Borase, C. Narkhede, A. Stevenson, J. Hallsworth and S. Patil, Int. J. Cosmet. Sci., 2015, 37, 98-107.

9 P. Bhaganna, R. J. Volkers, A. N. Bell, K. Kluge, D. J. Timson, J. W. McGrath, H. J. Ruijssenaars and J. E. Hallsworth, Microb. Biotechnol., 2010, 3, 701-716.

10 N. J. Amruthraj, J. P. P. Raj and A. Lebel, Appl. Nanosci., 2014, 5, 403-409.

11 E. Tolstik, L. A. Osminkina, C. Matthäus, M. Burkhardt, K. E. Tsurikov, U. A. Natashina, V. Y. Timoshenko,
R. Heintzmann, J. Popp and V. Sivakov, Nanomedicine, 2016, 12, 1931-1940.

12 A. Kumar, P. K. Vemula, P. M. Ajayan and G. John, Nat. Mater., 2008, 7, 236-241.

13 E. M. Hetrick and M. H. Schoenfisch, Chem. Soc. Rev., 2006, 35, 780-789.

14 K.-J. Kim, W. S. Sung, B. K. Suh, S.-K. Moon, J.-S. Choi, J. G. Kim and D. G. Lee, BioMetals, 2009, 22, 235-242.

15 A. Ranjitham, R. Suja, G. Caroling and S. Tiwari, Int. J. Pharm. Pharm. Sci., 2013, 5, 239-251.

16 H.-J. Eom and J. Choi, Environ. Sci. Technol., 2010, 44, 83378342.

17 M. J. Piao, K. A. Kang, I. K. Lee, H. S. Kim, S. Kim, J. Y. Choi, J. Choi and J. W. Hyun, Toxicol. Lett., 2011, 201, 92-100.

18 L. Ortega-Arroyo, E. S. Martin-Martinez, M. A. AguilarMendez, A. Cruz-Orea, I. Hernandez-Pérez and C. Glorieux, Starch, 2013, 65, 814-821.

19 S. Singh, P. Patel, S. Jaiswal, A. Prabhune, C. Ramana and B. Prasad, New J. Chem., 2009, 33, 646-652.

20 P. K. Brown, A. T. Qureshi, A. N. Moll, D. J. Hayes and W. T. Monroe, ACS Nano, 2013, 7, 2948-2959.

21 J. Yang, H. Wang, Z. Wang, X. Tan, C. Song, R. Zhang, J. Li and Y. Cui, Chin. Opt. Lett., 2009, 7, 894-897.

22 A. N. Brown, K. Smith, T. A. Samuels, J. Lu, S. O. Obare and M. E. Scott, Appl. Environ. Microbiol., 2012, 78, 2768-2774.

23 M. Rai, A. Yadav and A. Gade, Biotechnol. Adv., 2009, 27, 7683.

24 S. Saha, B. Gupta, K. Gupta and M. G. Chaudhuri, Appl. Nanosci., 2016, 1-11.

25 K. B. Ayaz Ahmed, S. K. Mahapatra, M. R. Charan Raja, S. Subramaniam, M. Sengan, N. Rajendran, S. K. Das, K. Haldar, S. Roy, A. Sivasubramanian and V. Anbazhagan, RSC Adv., 2016, 6, 18980-18989.

26 S. F. Altschul, T. L. Madden, A. A. Schäffer, J. Zhang, Z. Zhang, W. Miller and D. J. Lipman, Nucleic Acids Res., 1997, 25, 3389-3402.

27 T. A. Hall, BioEdit: a user-friendly biological sequence alignment editor and analysis program for Windows 95/98/ NT, Nucleic Acids Symposium Series, 1999.

28 N. Saitou and M. Nei, Mol. Biol. Evol., 1987, 4, 406-425.

29 W. M. Fitch, Syst. Biol., 1971, 20, 406-416.

30 J. Felsenstein, J. Mol. Evol., 1981, 17, 368-376.

31 K. Tamura, G. Stecher, D. Peterson, A. Filipski and S. Kumar, Mol. Biol. Evol., 2013, 30, 2725-2729.

32 R. S. Blosser and K. M. Gray, J. Microbiol. Methods, 2000, 40, 47-55.

33 C. Matz, P. Deines, J. Boenigk, H. Arndt, L. Eberl, S. Kjelleberg and K. Jürgens, Appl. Environ. Microbiol., 2004, 70, 1593-1599.

34 S. S. Naz, M. R. Shah, N. U. Islam, A. Khan, S. Nazir, S. Qaisar and S. S. Alam, J. Nanobiotechnology, 2014, 12, 34.

35 J. Sambrook, E. Fritsch and T. Maniatis, Molecular cloning: a laboratory manual, 1989, vol. 3.

36 I. Wiegand, K. Hilpert and R. E. Hancock, Nat. Protoc., 2008, 3, 163-175.

37 G. Prism, GraphPad Software Inc, San Diego, CA, USA, 2007. 
38 M. Serrano, M. Ramirez, D. Morilla, A. Valverde, M. Chávez, A. Espinel-Ingroff, R. Claro, A. Fernández, C. Almeida and E. Martín-Mazuelos, J. Antimicrob. Chemother., 2004, 53, 739-742.

39 A. Dakhama, J. De la Noüe and M. Lavoie, J. Appl. Phycol., 1993, 5, 297-306.

40 T. Hoshino, T. Hayashi and T. Odajima, J. Chem. Soc., 1995, 1565-1571.

41 C. Menezes, B. Silva, I. Sousa, A. Ruiz, H. Spindola, E. Cabral, M. Eberlin, S. Tinti, J. Carvalho and M. Foglio, Braz. J. Med. Biol. Res., 2013, 46, 65-70.

42 Y. Ohko, T. Tatsuma, T. Fujii, K. Naoi, C. Niwa, Y. Kubota and A. Fujishima, Nat. Mater., 2003, 2, 29-31.

43 W. Kleemann, Zeitschrift für Physik, 1968, 215, 113-120.

44 L. Rastogi and J. Arunachalam, Mater. Chem. Phys., 2011, 129, 558-563.

45 S. Subramaniam, V. Ravi and A. Sivasubramanian, Pharm. Biol., 2014, 52, 86-90.

46 F. A. Fakhr, A. Khanafari, M. Baserisalehi, R. Yaghoobi and S. Shahghasempour, Afr. J. Microbiol. Res., 2012, 6, 62356242.

47 N. Lubick, Environ. Sci. Technol., 2008, 42, 8617.
48 W.-R. Li, X.-B. Xie, Q.-S. Shi, H.-Y. Zeng, O.-Y. You-Sheng and Y.-B. Chen, Appl. Microbiol. Biotechnol., 2010, 85, 1115-1122. 49 A. Marques, R. Reis and J. Hunt, Biomaterials, 2002, 23, 1471-1478.

50 N. Durán, G. Z. Justo, C. V. Ferreira, P. S. Melo, L. Cordi and D. Martins, Biotechnol. Appl. Biochem., 2007, 48, 127-133.

51 S. Ashraf, M. A. Chatha, W. Ejaz, H. A. Janjua and I. Hussain, Nanoscale Res. Lett., 2014, 9, 1-10.

52 Y. Nakamura, C. Asada and T. Sawada, Biotechnol. Bioprocess Eng., 2003, 8, 37-40.

53 S. Y. Choi, K.-h. Yoon, J. I. Lee and R. J. Mitchell, BioMed Res. Int., 2015, 510386.

54 N. D. Fedorova, N. Khaldi, V. S. Joardar, R. Maiti, P. Amedeo, M. J. Anderson, J. Crabtree, J. C. Silva, J. H. Badger and A. Albarraq, PLoS Genet., 2008, 4, e1000046.

55 S. Bartnicki-Garcia, Annu. Rev. Microbiol., 1968, 22, 87-108. 56 R. N. Harris, R. M. Brucker, J. B. Walke, M. H. Becker, C. R. Schwantes, D. C. Flaherty, B. A. Lam, D. C. Woodhams, C. J. Briggs and V. T. Vredenburg, ISME J., 2009, 3, 818-824.

57 S. Anju, N. S. Kumar, B. Krishnakumar and B. D. Kumar, Front. Cell. Infect. Microbiol., 2015, 5, 57. 